\title{
UM CENÁRIO DE POSSIBILIDADES PARA O ESTÁGIO CURRICULAR SUPERVISIONADO NO CONTEXTO DE UM INSTITUTO FEDERAL
}

\author{
ROSENILDE NOGUEIRA PANIAGO ${ }^{*}$ \\ https://orcid.org/0000-0003-1178-8166 \\ TERESA JACINTO SARMENTO2** \\ https://orcid.org/0000-0002-2371-399X \\ JOSIANE MEDEIROS ${ }^{1 * *}$ \\ https://orcid.org/0000-0003-4505-9869 \\ PATRÍCIA GOUVÊA NUNES ${ }^{1 * * *}$ \\ https://orcid.org/0000-0001-7418-0583
}

RESUMO: Este artigo trata da pesquisa acerca da formação inicial de professores, focando o Estágio Curricular Supervisionado (ECS). O objetivo foi investigar o processo de estágio e buscar novas alternativas de atuação do docente recém-formado pelo viés da pesquisa. Neste texto, apresenta-se um recorte da pesquisa, que trata do atual modelo de prática do ECS e apresenta uma proposta de alteração pelo viés da pesquisa. Para tanto, utilizou-se, como metodologia, a análise de documentos, de fontes escritas e orais, além da observação in loco nas escolas em que os estudantes realizaram os estágios. Participaram quatro professores orientadores de estágio e quatro estagiários. Os resultados revelam que o estágio vem sendo realizado numa concepção de racionalidade técnica e, para a sua superação, é preciso que seja tratado como elemento articulador que perpassa as diferentes disciplinas que compõem a matriz curricular, e que ocorram reflexões coletivas para estudo, planejamento, execução e avaliação das ações.

Palavras-chave: Estágio em um IFET; Formação inicial de professores; Pesquisa na formação.

\section{UN ESCENARIO DE POSIBILIDADES PARA LA PASANTÍA CURRICULAR SUPERVISADA EN EL CONTEXTO DE UN INSTITUTO FEDERAL}

RESUMEN: Este artículo trata de la investigación acerca de la formación inicial de maestros, enfocada en la Pasantía Curricular Supervisada (PCS). El objetivo fue investigar el proceso de pasantía y buscar nuevas alternativas de actuación del docente recién graduado por la tendencia de la investigación. En este texto, se presenta un recorte de investigación que trata
"Doutora em Educação pela Universidade do Minho, Portugal. Professora do Instituto Federal Goiano. Professora Colaboradora no

Programa de Pós-Graduação em Educação para Ciências e Matemática (PPGECM)/

IFG. Líder do grupo de pesquisa EducAção do Instituto Federal Goiano e faz parte do grupo InvestigaAção da Universidade Federal de Mato Grosso, com pesquisas nas áreas de formação de professores, saberes e prática docente.

E-mail:<rosenilde.paniago@ifgoiano.edu.br $>$.

“Doutora em Estudos da Criança, Professora Auxiliar do Instituto de Educação da Universidade do MinhoPortugal, Membro Integrado do Centro de Investigação em estudos da Criança, Diretora do Curso de Mestrado em

Educação Pré-escolar e Ensino do $1^{\circ}$ Ciclo do Ensino Básico daquela universidade. E-mail:<tsarmento@ie.uminho.pt >

"."Mestra em Educação pela Universidade Federal de Goiás, na linha de pesquisa Políticas Educacionais, Gestão e Formação de Professores. Pedagoga, Instituto Federal Goiano - Campus Rio Verde. Membro do grupo de pesquisa EducAção do Instituto Federal Goiano.

E-mail:<josiane.medeiros@ifgoiano.edu.br > .

"..."Mestra em Educação pela Pontifícia Universidade Católica de Goiás - PUC -GO, na linha de pesquisa Estado, Políticas e Instituições Educacionais. Professora do Instituto Federal Goiano, Campus Rio Verde-GO. Membro do grupo de pesquisa EducAção do Instituto Federal Goiano. E-mail:<patricia.nunes@ifgoiano.edu.br >.

\footnotetext{
${ }^{1}$ Instituto Federal Goiano, GO - Brasil.

${ }^{2}$ Universidade do Minho, Braga - Portugal.
} 
del modelo actual de práctica de la PCS y presenta una propuesta de alteración por la tendencia de la investigación. Para tanto, se ha utilizado como metodología el análisis de documentos, fuentes escritas y orales, además de la observación in loco en las escuelas en las que los estudiantes realizaron sus pasantías. Participaron cuatro profesores orientadores de pasantía y cuatro pasantes. Los resultados revelan que la pasantía es realizada en una concepción de racionalidad técnica y, para su superación, es necesario que sea tratada como un elemento articulador que permea las diferentes asignaturas que componen la matriz curricular, y que ocurran reflexiones colectivas para estudio, planeamiento, ejecución y evaluación de las acciones.

Palabras clave: Pasantía; Formación Inicial de Maestros; Investigación en la Formación.

\section{A POSSIBILITY SCENARIO FOR SUPERVISED CURRICULAR INTERNSHIP IN A FEDERAL INSTITUTE}

ABSTRACT: This article reports of the research about the initial formation of teachers, focusing on the Supervised Curricular Internship (SCI). The main goal was to investigate the internship process and search for new alternatives of action for the recently graduated teacher. In this paper, we present a framed research about the current SCI model and proposes an alteration through research bias. For this purpose, we accessed action research methodology, analyzing written documents, oral sources and on-site observation in schools where teaching students perform internships. Four teachers and four interns took part on the research. The results show that the internship has taken place in a technical rationality conception. For its overcoming, internship has to be treated as an articulating element that crosses the different disciplines that are part of the curricular matrix. It's also necessary that collective reflections are made about study, planning, implementation and evaluation of actions.

Keywords: Internship; Teacher training; Research in teacher training. 


\section{INTRODUÇÃO}

O presente texto apresenta o resultado da pesquisa acerca da formação inicial de professores, focando o Estágio Curricular Supervisionado (ECS), componente da matriz curricular dos cursos de Licenciatura em Química e em Ciências Biológicas do Instituto Federal de Educação, Ciência e Tecnologia, aqui identificado como IF. As análises a serem tratadas no presente artigo são referentes ao ECS, seu modelo de prática e a busca de novas alternativas de alteração da proposta, visando melhorias na formação e atuação do futuro professor.

Ao propor um estudo acerca da formação de professores, tendo como objeto o ECS das Licenciaturas no contexto de um Instituto Federal de Educação, Ciência e Tecnologia (IFET), com o intuito de associar a pesquisa como elemento formativo, é possível prever que se trata de uma empreitada desafiante, uma vez que discutir o tema "pesquisa" na formação e prática docente é, em si, um exercício árduo, complexo e repleto de desafios. Tal desafio é potencializado em instituições que possuem uma história já consolidada no campo das engenharias, das ciências agrárias, enfim, da formação técnica para o trabalho e com uma experiência reduzida na formação de professores.

Para além disso, de modo geral, a formação inicial de professores não tem dado conta de prepará-los para enfrentar os desafios emergentes do cotidiano escolar. O estágio, foco do presente estudo, tem se constituído no processo formativo de muitas instituições em atividades fragmentadas, dicotômicas e sustentadas no paradigma da racionalidade técnica (PIMENTA; LIMA, 2017), fato que não possibilita aos estagiários desenvolverem posturas investigativas e reflexivas acerca da realidade educacional.

Não obstante, ressalta-se a recente experiência dos IFETs com a formação de professores, que se inicia a partir da exigência da Lei $\mathrm{n}^{\circ}$ $1.892 / 2008$ que os cria e os obriga a ofertar no mínimo $20 \%$ (vinte por cento) das vagas aos cursos de licenciatura. Então, essas instituições, criadas a partir de 1909, possuem um histórico de mais de 100 anos consolidados na formação técnica para o trabalho, o que implica a necessidade e importância de pesquisas que procurem diagnosticar as fragilidades por meio de um processo cíclico de ação e reflexão.

É em meio a essa complexidade, que um grupo de professores de uma unidade do IF, contando com o apoio de dois professores do Instituto de Educação da Universidade do Minho, Portugal, resolveu pesquisar o atual modelo de ECS adotado no intuito de superá-lo. Diante do exposto, no âmbito desse estudo, objetiva-se a possibilidade de um processo formativo que vá além daquele que ainda contribui para a formação de professores como técnicos, considerando que, na contemporaneidade, o professor, além de dominar os conhecimentos científicos, técnicos e práticos precisa ter um olhar reflexivo e investigativo sobre a sua prática. O grupo de professores entendeu que o modelo de ECS a ser proposto pelo IF é o de estágio pelo viés da pesquisa, de forma a permear toda a formação, objetivando o ECS numa perspectiva epistemológica, em que se produz numa interação entre os sujeitos envolvidos e os contextos escolares, futuro campo de trabalho dos licenciandos. 
O modelo de estágio pelo viés da pesquisa foi balizado nos teóricos que defendem esta perspectiva formativa, como Pimenta e Lima (2017), Almeida e Pimenta (2014) e Vieira (2015), e na experiência das práticas de ECS da Universidade do Minho com a formação inicial de professores, em que a investigação é componente muito importante no processo formativo.

Neste texto, apresentam-se dados parciais da investigação, conduzidos pelos seguintes questionamentos: Como o ECS se desenvolve nos cursos de Licenciatura do IF? Quais as possibilidades e vulnerabilidades para a implantação de um processo de ECS sob o viés da pesquisa? Que caminhos seguir para a elaboração de uma proposta de ECS pelo viés da pesquisa?

\section{METODOLOGIA}

A proposta de um estudo, tendo como objeto a prática de ECS, associando-se à pesquisa como elemento formativo, incita a necessidade de uma proposta metodológica que permita visualizar o invisível, desvelar o que não está explícito. Para tanto, ela não se consolida sem um estudo prévio das condições e modelos de oferta, até então, desenvolvidos no IF, bem como sem a leitura atenta da documentação pertinente à proposta de ECS.

Desta forma, a imprevisibilidade dos fenômenos educativos implica na ação e reflexão, bem como na avaliação e replanejamento dos caminhos da pesquisa, pois, conforme afirmam Ghedin e Franco (2008), não é possível apreender a teia de relações e práticas escolares por meio de métodos objetivos, estanques e distanciados dessas relações históricas e sociais.

A pesquisa conta com as seguintes fases de execução: 1) levantamento do modelo de oferta do ECS do IF; 2) elaboração de uma proposta de ECS; 3) acompanhamento perspectivado na pesquisa-ação. ${ }^{1}$ Atualmente, a pesquisa se encontra na terceira fase, portanto, o levantamento do modelo e elaboração da nova proposta já foram realizados. É sobre tais elementos, já constituídos em dados, que trata o presente texto. Futuramente, apresentar-se-ão os resultados do acompanhamento da proposta elaborada.

Para o levantamento do modelo de estágio do IF, realizou-se revisão bibliográfica da temática, análise de documentos de fontes escrita e orais (colhidos através de entrevistas) e observação in loco nas escolas onde os estudantes dos cursos das Licenciaturas em Química e em Biologia do IF, realizam os estágios. As entrevistas foram realizadas com quatro professores orientadores de estágio e quatro estagiários, sendo dois do curso de Química e dois do curso de Biologia. Como critério de seleção dos orientadores, optou-se pela escolha de professores com mais de dois anos de orientação de estágio. No caso dos discentes, a escolha se ateve a licenciandos que estivessem no segundo ano de ECS. As entrevistas e as observações ocorreram entre os anos de 2014 e 2015, em que foi observado o desenvolvimento de projetos de cunho investigativo exploratórios, realizados pelos estagiários. Como documentos foram analisados a matriz curricular, o Projeto Pedagógico do Curso (PPC) e o regulamento de ECS.

A terceira fase da pesquisa versa sobre o processo de acompanhamento perspectivado na pesquisa-ação e encontra-se em andamento. 


\section{O ESTÁGIO CURRICULAR SUPERVISIONADO NA FORMAC̣ÃO INICIAL DOCENTE}

$\mathrm{Na}$ Resolução CNE/CP n ${ }^{\circ}$ 2/2002, de 19 de fevereiro, que delibera sobre a carga horária dos cursos de Licenciatura, de graduação plena de formação de professores da Educação Básica em nível superior, é estabelecida a carga horária mínima de 400 horas para o ECS, com início a partir da segunda metade do curso. A atual Resolução CNE/CP no 02/2015, de 2 de julho, que define as Diretrizes Curriculares Nacionais (DCN/2015) para a formação inicial e continuada, mantem esta mesma carga horária e afirma que o ECS deve ser uma atividade articulada com a prática e com as demais atividades dos cursos de Licenciatura.

Assim, o ECS é componente curricular obrigatório e tem como objetivo o desenvolvimento de saberes da docência por meio da articulação teoria-prática e vivência de situações do trabalho docente. Como afirmam Paniago e Sarmento (2015, p.77), o ECS é importante, “[...] por possibilitar a aproximação do formando com sua futura profissão, permitir-lhe vivenciar práticas de ensino, estabelecer a relação teoria-prática, conviver com a complexidade do cotidiano escolar e, sobretudo, experienciar práticas de interação educativa com os alunos".

No presente estudo, defende-se a superação do estágio como, somente, parte prática dos cursos de formação inicial de professores e mero componente curricular para a efetivação do mesmo como um elemento articulador, que perpassa todas as disciplinas integrantes do corpo de conhecimento e se concretiza por meio da pesquisa. Não obstante, ressalta-se a importância do diálogo e valorização da escola de educação básica e dos profissionais que nela atuam como coformadores no processo de estágio, sendo forma de superação do processo dicotômico das práticas de ensino dos professores das IES com a realidade da escola de educação básica. Conforme Ludke (2009, p. 99), “[...] se trata de dois universos, inteiramente distintos entre si. Os professores, formadores de futuros educadores para a educação básica, não têm uma visão sequer razoável da realidade desses sistemas de ensino e não têm, em sua maioria, nenhuma vivência nele, como professores". Por sua vez, Zeichner (2010) afirma que o desafio dos programas tradicionais de formação de professores traduz-se pela falta de conexão entre os cursos das IES e o campo da prática, ou seja, o cotidiano da escola de educação básica.

Evidencia-se, portanto, a importância da escola como local privilegiado para a aprendizagem de ser professor, sendo o ECS um espaço especial para estas aprendizagens. Conforme Almeida e Pimenta (2014), o ECS oportuniza a aproximação com o ambiente de trabalho, com as práticas didático-pedagógicas e com os alunos e os professores, possibilitando aos estudantes diagnosticar dados, observar a prática dos supervisores, refletir e analisar buscando vincular “[...] as teorias estudadas com as situações práticas, procurando articular os vários elementos que estão percebendo na realidade observada de modo que avancem no seu desenvolvimento pessoal e na constituição dos seus estilos de atuação (ALMEIDA; PIMENTA, 2014, p. 29).

As autoras atribuem ao ECS um estatuto epistemológico que supera a dicotomia teoria e prática e o concebem como práxis, apontando a pesquisa como caminho metodológico para o seu desenvolvimento. A visão proposta neste trabalho assenta nesta perspectiva formativa apontada por Almeida e Pimenta (2014), pois 
acredita-se ser o estágio um momento fecundo para o desenvolvimento de práticas investigativas, reflexivas para que os futuros professores possam assumir a postura de produtores de conhecimento a partir das situações complexas de seu trabalho e não como operários que se atêm à sua transmissão. Enfim, um professor questionador, que reflete sobre sua prática e procura soluções para os problemas que surgem em sala de aula, e colaborativamente, busca, por meio da intervenção em sua realidade educativa, alternativas para as desigualdades de ordem social, política e ambiental. Defende-se, portanto, um perfil de profissional tal como realçam Pimenta e Lima (2017, p. 39), "O professor que queremos formar é o profissional crítico-reflexivo, pesquisador de sua práxis docente e da práxis que ocorre nas escolas".-

Acerca da investigação como estratégia de formação no processo de ECS, cita-se também a experiência portuguesa após a implementação do processo de Bolonha, ${ }^{2}$ com a revisão da Lei de Bases do Sistema Educativo, por meio de Decretos-Lei. No caso da investigação na formação, é possível constatar que no Decreto-Lei $n^{\circ} .43 / 2007$, que trata das atribuições de habilitação para a docência, é suscitada a relevância da pesquisa, além da importância do conhecimento disciplinar. Nisso a investigação na formação:

[...] dá-se especial ênfase à área das metodologias de investigação educacional, tendo em conta a necessidade que o desempenho dos educadores e professores seja cada vez menos o de um mero funcionário ou técnico e cada vez mais o de um profissional capaz de se adaptar às características e desafios das situações singulares em função das especificidades dos alunos e dos contextos escolares e sociais. (PORTUGAL, 2007, p. 1321).

Segundo Sarmento e Paniago (2016), no contexto das mudanças após o processo de Bolonha, o ECS é um espaço privilegiado para o desenvolvimento da prática de investigação. Para as autoras, a investigação ao serviço das práticas foi valorizada e deve ter em vista a promoção de competências pelos estudantes de modo a sustentar a sua própria construção de conhecimento profissional.

Acerca do ECS orientado pela pesquisa, cita-se também a experiência de Lima e Costa (2014), com o curso de Pedagogia da Universidade do Estado do Ceará em que as autoras compartilham uma experiência dos licenciandos com alunos da Educação de Jovens e Adultos consubstanciada na reflexão e na pesquisa. Para as autoras "Posturas investigativas no decorrer do estágio podem conduzir à construção de um conhecimento a respeito do fenômeno educativo que se revela por meio de atividades e ações pedagógicas ligadas ao ensinar e ao aprender a prática docente" (LIMA; COSTA, 2014, p. 48).

Silvestre (2016), por sua vez, apresenta o Programa Residência Pedagógica (PRP) do curso de Pedagogia da Universidade Federal de São Carlos, como uma experiência inovadora de prática de estágio. Segundo a autora, o PRP é inovador por desenvolver-se de forma articulada aos princípios do projeto de formação do curso e vinculado às atividades das escolas campo, "[...] por meio de uma metodologia própria, que possibilita não só a "apropriação do processo do trabalho pedagógico", mas também uma "sólida formação teórica, inter e transdisciplinar sobre o fenômeno educacional e seus fundamentos históricos, políticos e sociais” (SILVESTRE, 2016, p. 151). 
Acerca desta discussão no contexto dos IFETs, não foi possível identificar muitos trabalhos. Destaca-se Paes (2017), ao procurar sinalizar o papel mobilizador do ECS sobre a aprendizagem da docência de licenciandos do Instituto Federal Fluminense. A autora destaca que o estágio oportuniza condições teórico-práticas fundamentais para o exercício da docência, entretanto, não necessariamente o focaliza pelo viés da pesquisa; destaca-se também Silva, Fernandes e Quadro (2016), ao sinalizarem no curso de Licenciatura em Pedagogia do Instituto Federal Catarinense, elementos que evidenciam empenho da equipe em garantir o processo de atuação dos acadêmicos na perspectiva da práxis.

\section{O ESTÁGIO PELO VIÉS DA PESQUISA NA FORMAC̣ÃO INICIAL DE PROFESSORES}

A discussão do estágio pelo viés da pesquisa tem suas origens, segundo Pimenta e Lima (2017), na década de 1990, decorrente dos questionamentos e inquietações acerca da dicotomia teoria e prática no processo do ECS nas instituições formadoras de professores. Decorre também de uma reação à ideia dos professores como técnicos, meramente reprodutores de informações em sala de aula e aplicadores de reformas educacionais elaboradas de cima para baixo.

Ghedin e Almeida (2011) elucidam que o ECS, por meio da pesquisa, incita os estagiários a desenvolverem uma postura de pesquisador a partir das situações observadas no campo. Os autores demonstram, a partir de experiência realizada com uma turma do curso Normal Superior da Universidade do Estado do Amazonas, como a experiência da formação na e pela pesquisa pode materializar-se na formação inicial de professores durante o processo de ECS. Para tanto, os autores alertam que, para formar o professor-pesquisador, é necessário "o desenvolvimento de um período de estágio vinculado à pesquisa, a discussão dos conceitos que constituem o processo formativo docente [...]" (GHEDIN; ALMEIDA, 2011, p. 77).

A pesquisa, como componente fundamental da formação e prática docente, está presente também nas DCN/2015. Entre outras questões, é indicado que a formação de professores deve conduzir o futuro professor " [...] à construção do conhecimento, valorizando a pesquisa e a extensão como princípios pedagógicos essenciais ao exercício e aprimoramento do profissional do magistério e ao aperfeiçoamento da prática educativa" (Resolução CNE no 02/2015, p. 24). Infere-se, portanto, que a legislação incita a pesquisa como necessária, para que os futuros professores possam aprimorar a sua prática, na perspectiva da práxis.

A visão sobre pesquisa, proposta neste trabalho, compactua com DinizPereira e Lacerda (2009), os quais propõem um significado de pesquisa na prática docente, em uma perspectiva coletiva realizada no contexto escolar que fortalece o trabalho dos professores, incitando-os a sistematizar o conhecimento produzido:

[...] trata-se de uma investigação desenvolvida no cotidiano escolar e compreendida como discussão permanente acerca do currículo, da prática e da problemática social. Trata-se ainda de uma pesquisa que possibilita a professores e professoras das escolas se firmarem na qualidade de sujeitos que autogerenciem a sua própria formação, auxiliados pelo conhecimento teórico tomado como texto dialógico junto à tecitura do cotidiano escolar. [...] (DINIZ-PEREIRA; LACERDA, 2009, p. 1232-1233). 
Suporta-se, ainda na visão de Vieira (2015, p. 6), ao propor a pesquisa pedagógica, uma investigação que "[...] deve estar ao serviço da pedagogia e que deve estar ao serviço do desenvolvimento do estudante e do professor, e desenvolvida com objetivos claros".

O exposto reforça o intuito desta investigação e demonstra a necessidade de uma reflexão sobre a forma como é desenvolvido o estágio no IF. A reflexão apresentada contribuirá para fortalecer e ampliar a discussão acerca da pesquisa na formação e prática docente, e, por conseguinte, ajudará a repensar e incrementar o ECS, pelo viés da pesquisa, visão que ora se defende.

\section{O ECS DO IF: FRAGILIDADES, POTENCIALIDADES E NOVA PROPOSTA PELO VIÉS DA PESQUISA}

As informações, recolhidas nas fases de levantamento do modelo de oferta do ECS do IF e a elaboração de uma proposta de ECS para o IF, foram sistematizadas em três eixos de análise: 1) As fragilidades do atual modelo de ECS do IF; 2) As potencialidades do atual modelo para a implantação do ECS pelo viés da pesquisa; 3) A nova proposta de ECS.

\section{As fragilidades do atual modelo de ECS no IF}

No âmbito deste estudo, as análises revelam que ocorrem fragilidades no processo formativo deECS, dentre as quais destacam-se: a) desconexão teoria-prática; b) ausência de reflexão coletiva; c); fragilidade nas condições de acompanhamento do estagiário; 4) ausência de formação pedagógica dos professores.

Como primeira fragilidade, destaca-se a dissociação entre os conhecimentos apreendidos na formação e a prática da educação básica, futuro espaço de trabalho dos licenciandos. Uma das estagiárias denuncia isto, "o que vemos no curso pouco me ajuda a ser professora. Os professores trabalham conteúdos que nunca vou utilizar lá. Tem professor que nem a metodologia ajuda, pois é aulão com data show direto; meus colegas já chamam de data sono [...]" (EA, 2014). Na mesma direção, outra se pronuncia: "Sempre me pergunto, onde eu vou aplicar tudo isto que vejo aqui? [...] poucas vezes, os professores explicam para que servem os conteúdos. Sobre ser professor, sobre estágio, vejo mesmo é nas aulas de Didática e Prática de Ensino". Conforme observa-se, as formandas não conseguem perceber as finalidades dos conhecimentos trabalhados e como eles se aplicarão em sua futura prática docente.

Não obstante, observou-se que os conteúdos específicos, além de dominarem a maior parte da matriz curricular das Licenciaturas, são trabalhados, por vezes, sem conexão com as práticas da escola de educação básica, o que configura o modelo da racionalidade técnica. Para Ludke (2009), os estudos que tratam da formação de professores têm apontado a necessidade de romper-se com o modelo de formação ancorado, de início, no trabalho com conteúdos específicos de cada área e em que no final do curso são trabalhadas as disciplinas de prática de ensino e ECS, momento em que os licenciandos aplicam o que aprenderam na teoria. Para a autora, este modelo comum em muitas IES no país é um obstáculo ao processo formativo de professores. 
Ademais, verifica-se que as discussões pertinentes ao ECS são reservadas apenas para as disciplinas pedagógicas, especialmente, para a disciplina de Prática de Ensino. Esse fenômeno unidirecional agrava-se porque o diálogo entre as disciplinas que compõem o currículo é aplicado supondo uma linha de conexão imaginária que liga as atuações docentes, conforme prescreve-se numa proposta arbórea de currículo. Essa orientação cria uma ideia de que a formação de professores é uma tarefa exclusiva das disciplinas pedagógicas. Isso desmotiva e implica num trabalho solitário a ser desenvolvido pelo estagiário.

Nessa esteira, o ECS torna-se uma mera atividade prática, técnica, em que os futuros professores desenvolvem um papel de simples transmissores de didáticas, planos de aula, preenchendo fichas e elaborando relatórios, sem perceberem a importância da reflexão para a sua formação. Consequentemente, ao término do curso, ao ingressar como profissional no ambiente escolar, não desenvolvem práticas alternativas e criativas; ao contrário, tornam-se reprodutores de informações e de conhecimentos científicos, ou seja, a prática do profissional docente se resume em seguir a sequência didática apresentada nos livros didáticos, no cumprimento das orientações curriculares previstas nos sistemas estaduais e municipais de ensino.

Esse não é um fato isolado no IF, visto que é uma situação recorrente em outras instituições. Conforme Pimenta e Lima (2017, p. 37), a atividade de estágio, em muitas instituições, “[...] fica reduzida à hora da prática, ao como fazer, às técnicas a ser empregadas em sala de aula, ao desenvolvimento de habilidades específicas do manejo de classe, ao preenchimento de fichas de observação, diagramas, fluxogramas.".

A segunda fragilidade, observada no processo de ECS do IF, refere-se à ausência de reflexão coletiva. Apesar de o regulamento dos cursos de Licenciatura prever reuniões entre coordenação de estágio e professores orientadores para reflexão coletiva e avaliação das atividades de estágio, esta ação não ocorre, o que acarreta orientações truncadas, desprovidas da corporeidade material teórica e diretiva, conforme evidenciam os depoimentos dos professores: "Ah, não ocorre reuniões entre os professores que orientam o estágio, não há um planejamento, cada um orienta da forma como pensa e do seu jeito [...] o que dá mesmo para avaliar é o relatório, as fichas [...] Cada um por si” (PS, 2014). Na mesma direção, pronunciam-se outros dois professores orientadores:

Eu faço do meu jeito, indico pesquisas, projetos para serem desenvolvidos, [...] cada aluno escolhe o seu orientador e a gente faz da forma como achar melhor. Eu estou aqui na instituição desde 2009 e, até hoje, nunca sentei com mais que três professores para discutir estágio (PL, 2015).

[...] talvez seja uma falha até do grupo mesmo de não se reunir para discutir essa questão de orientação. Nas reuniões do NDE não trataram disso; não me lembro de ter nenhuma reunião tratando sobre questão de estágio e eu estou nessa função de coordenador já há bastante tempo. Talvez até por falha minha não ter tido nenhuma reunião falando deste tipo de troca de experiência (PC, 2015). 
É nesse sentido que fica evidente a falta de articulação entre a base teórica da prática do estágio e orientadores, ou seja, um sistema formativo baseado na racionalidade técnica. Por certo, de modo geral, as ações do atual ECS têm como coluna dorsal a observação e elaboração de relatório, sem que seja possibilitada uma formação na perspectiva da reflexão da ação, em que os participantes do processo, coordenação de ECS, professores orientadores, professores supervisores e estagiários reflitam sobre as ações realizadas durante o processo de estágio de forma coletiva.

A inexistência de ações coletivas para reflexão das ações pertinentes ao ECS promove uma desarticulação curricular na instituição, e prevalece a realização de pesquisas, desvinculadas ao ensino, dissociadas da prática dos docentes, segregada em laboratórios por meio de demonstração, experimentação e prova. Isto é preocupante, porque mesmo que os estagiários sejam orientados a fazer elaborações em grupo e a trabalhar juntos na escola durante a disciplina de Prática de Ensino, no desenvolvimento do ECS, a orientação é distribuída entre todos os professores que lecionam nos cursos de Licenciatura, fato que provoca a fragmentação e descontinuidade das ações a serem realizadas via projetos. Assim, cada orientando segue uma linha para o desenvolvimento das ações do ECS, de acordo com a concepção de Educação, Ciência e formação de seu orientador. Uma formadora reconhece a importância das reuniões: "O que torna o estágio ser mais difícil é falta de troca de experiência. [...] pensar em qual é a melhor saída; porque é difícil a gente tomar uma decisão individualmente" (PL, 2015). Na mesma direção, outra se expressa:

Nós precisamos de reunião, estudo, para discutir os pontos do estágio [...] isto me ajudará muito. Eu não sei nem como eu orientei os meus alunos, pois não tenho prática nenhuma de orientação de estágio. Quando tenho muita dúvida sobre o estágio, muitas vezes não sei mesmo a quem me reportar [...]. Eu me sinto desamparada para a orientação do estágio (PS, 2014).

Evidentemente, se houvesse encontros formativos, reuniões para reflexão sobre as práticas do ECS, muitos problemas que ocorrem seriam amenizados. Nesta perspectiva, considera-se que este é um obstáculo a ser superado para que o ECS, pelo viés da pesquisa, seja concretizado no IF. Ademais, estes encontros formativos devem ser estendidos aos professores da escola de educação básica, que também participam do processo formativo dos estagiários. Lima e Aroeira (2011) contribuem ao afirmarem que a operacionalização de práticas colaborativas possibilita a reflexão compartilhada entre os formadores:

[...] estratégia que, no âmbito da aprendizagem profissional, é conceituada como momentos de socialização de saberes, problematização e produção de conhecimento por meio de uma postura investigativa que se possibilita ao professor estagiário, ao professor orientador de estágio e aos demais estagiários a chance de contribuir para a ampliação da comunicação entre a universidade e a escola, além de assumir uma conduta ativa diante do conhecimento (LIMA; AROEIRA, 2011, p. 117). 
Zeichner (2010) propõe a criação de novos espaços híbridos que integre os diversos tipos de conhecimentos para outras formas que aprimorem a aprendizagem dos formandos sem dicotomizar a teoria e a prática.

Como terceira fragilidade, salienta-se as condições de acompanhamento dos estagiários em que se destacam as inúmeras atividades dos professores orientadores que os impedem de acompanhar frequentemente, e o fato de muitos estagiários residirem a longa distância da instituição, em outras cidades, conforme afirma esta professora: "Os alunos ficam isolados ao realizar o estágio. Às vezes, nem nos procuram, pois moram em outras cidades. Tem alunos que apresentam as aulas em vídeos, porque não podemos ir até sua cidade [...]" (PS, 2014). Na mesma direção, testemunha outro professor: "É difícil orientar os alunos, pois nossos cursos de licenciatura possuem muitos alunos de outra cidade; fica ainda mais difícil de acompanhar; não dá para afirmar que sabemos de todo o andamento do estágio de cada orientado nosso" (PC, 2014).

Além de muitos estagiários residirem em outras cidades que distam até $100 \mathrm{~km}$ da instituição, soma-se o fato de não terem disponibilidade para a orientação durante o dia, pois, como estudam no período noturno, no diurno necessitam trabalhar.

Outrossim, frequentemente, o comprometimento com as atividades de ECS fica a desejar. Outro agravante decorre da falta de tempo dos orientadores para acompanharem os estagiários, conforme aponta uma estagiária:

\footnotetext{
A professora orientadora, ela até procurou me ajudar, mas parecia que não tinha tempo, pois era difícil da gente conseguir falar com ela. Fiz o estágio meio que perdida. Mas ela foi assistir minha aula na escola e apontou o que eu devia descrever no relatório. Senti dificuldade de realizar o projeto na escola, pois não tive muito orientação por parte do professor e aceitação na escola (EA, 2014).
}

Neste relato, a estagiária sinaliza a ausência de orientação frequente por parte do orientador da IES, ao que atribui a falta de tempo, fato que influenciou negativamente o desenvolvimento do ECS, na medida em que não tinha informação e apoio do professor orientador e da própria escola para a operacionalização das atividades. Verifica-se, portanto, que mesmo que a professora tenha ido à escola para assistir a uma de suas aulas, esta participação não foi suficiente para que a aluna tivesse o apoio necessário à realização das ações previstas no ECS. A esse respeito manifesta outra estagiária:

Deveria ser oferecido maior apoio aos estagiários; [...] me senti sem saber o que fazer, pois têm muitas informações, algumas divergentes, e confunde. Um manual do estagiário das licenciaturas não seria nada mal. Poderia ter experiências de estagiários, como agir na sua primeira aula, como lidar com os alunos mais difíceis, o que fazer nas observações para não se sentir um corpo estranho, enfim muitas dicas para auxiliar o estagiário. Talvez um contato mais próximo com o orientador tivesse me ajudado (EJ, 2014). 
Também uma professora orientadora afirma que "a gente não se dedica todo o tempo destinado para acompanhar o estagiário lá na escola. Não tenho esse horário; então eu acho que a gente teria que ter um tempo determinado na semana [...]" (PL, 2015). Outra professora diz também que: "Eu tive 10 estagiários, apenas um eu tive mais contato. Os outros se perderam no caminho. Não consegui de fato acompanhar, salvo quando fui à escola avaliar a aula" (PS, 2014). Reconhece-se que os professores orientadores não podem ser culpabilizados pelo não acompanhamento frequente aos estagiários, na medida em que se envolvem em muitas atividades na instituição e atuam em diferentes níveis. Entretanto, é necessário pensar em uma alternativa para que o ECS não seja prejudicado.

Por fim, como quarta fragilidade, salienta-se a ausência de formação pedagógica dos professores. Muitos deles, que atuam nas Licenciaturas e ECS, não possuem formação na área do ensino e da educação e/ou experiência com pesquisa pedagógica. No caso dos professores orientadores participantes desta pesquisa, todos são licenciados, entretanto, somente um realizou mestrado na área do ensino, os demais realizaram a pós-graduação (mestrado e doutorado) em suas áreas específicas de Química ou Biologia e permanecem desenvolvendo pesquisas nestas áreas no IF.

A ausência de formação nessa área certamente é um fator que não favorece uma preparação adequada de orientação do estágio e a operacionalização do ECS pelo viés da pesquisa pedagógica, o que se agrava caso o professor trabalhe individualmente. Sobre a pesquisa em educação afirma um dos orientadores:

Eu diria que a pesquisa em educação está em processo pré embrionário. Nesse aspecto, na área de pesquisas para fomentar para resolver os problemas, para propor soluções pensando na prática da educação básica. Aí a gente precisa de recursos humanos, precisa de servidores que se predisponham; porque precisa e não é obrigatória; você não tem obrigação nenhuma. Seu salário no final do mês é o mesmo se você se envolver, é querer gerar conhecimento ou não, só quero transmitir (PE, 2015).

O professor aponta a necessidade de os formadores se predisporem a trabalhar com a pesquisa, fato importante, pois sem interesse é mesmo impossível um professor se dedicar a atividades de pesquisa. Entretanto, o que se verifica na instituição é que as pesquisas experimentais em áreas específicas possuem demasiado valor e potencial,

Eu acho que não acontece a pesquisa no ensino; falta estímulo e também falta um perfil na área do curso de licenciatura, na área de educação. Temos uma lacuna porque o curso da Biologia está bem estruturado na área da biologia animal; na área da genética, microbiologia. Agora não temos perfil de professores da área de educação [...] (PL, 2015).

Eu acho que na nossa instituição não existe esta relação da pesquisa com o ensino. É tudo isolado. Tem o grupo da pesquisa, o grupo do ensino e da extensão. Eu vejo que a pesquisa está muito longe, isolada, em termos de apoio. Eu desenvolvo pesquisa, mais na área de Química. Eu desenvolvo pesquisas na área ambiental, mas não é o foco o ensino, a educação, a formação de professores (PS, 2014). 
Conforme a professora PL aponta, o curso de Biologia está bem estruturado, com professores que se dedicam a pesquisas em sua área de formação, enquanto que na área de educação, não existe perfil de professores. Já a professora PS, do curso de Química, expõe que não há apoio na instituição para a pesquisa vinculada ao ensino, inclusive, destaca que desenvolve pesquisa operacionalizada na sua área de formação. Para ela, a falta de apoio não propicia o desenvolvimento desta atividade "não temos um direcionamento, então não me sentia a vontade em desenvolver uma pesquisa na educação sem ter um apoio, um estudo [...]. Sozinha não consigo” (PS, 2015).

Assim, é possível afirmar que prevalece uma forte valorização da pesquisa em área específica em detrimento da pesquisa vinculada ao ensino. Desta situação, pode-se inferir que um dos dilemas do IF está na formação dos professores que atuam nas Licenciaturas; majoritariamente, são bacharéis ou licenciados com pósgraduação em áreas específicas. A esse respeito, testemunha uma das professoras: "Eu acho que nós poderíamos aprender, ter uma formação pedagógica para dar a base para fazer uma pesquisa em educação [...], eu aprendi a fazer pesquisa em Biologia animal, não tenho prática em educação (PL, 2015). A esse respeito também se pronuncia outra professora: "Falta um diálogo ou cursos preparatórios para os professores poderem melhor ensinar os alunos a trabalhar ali no estágio fazer uma relação com a pesquisa" (PS, 2014).

Outro professor diz que a ausência de formação pode acarretar uma visão tecnicista sobre o ensino e a pesquisa, influenciando inclusive os alunos:

[...] pode formar um professor que tenha uma visão tecnicista, uma visão não tão aberta para várias vertentes; são visões que são muito centradas. Até mesmo sobre pesquisa; porque, às vezes, você conversa com um estudante e ele diz que quer fazer pesquisa, mas pesquisa centrada em bancadas, no laboratório. Não uma pesquisa onde se faz um questionário e se investiga uma comunidade, etc. (PC, 2015).

O depoimento do professor PC sinaliza um aspecto preocupante, que pode entravar a perspectiva formativa do estágio pelo viés da pesquisa aqui defendida, na medida em que a área de formação do professor formador, a sua concepção de educação e ciência influencia de forma significativa a sua atuação enquanto professor, pesquisador e orientador de estágio.

Por certo, a ausência de formação inicial e continuada, acerca dos fenômenos da educação (pesquisa pedagógica, metodologias, currículo, concepções teóricoepistemológicas dos fundamentos da educação, dentre outros aspectos), negligencia, aos estagiários, a aprendizagem de aspectos fulcrais da docência - o que, como, para quem, para que ensinar - e a capacidade de mobilizarem por meio da reflexão e investigação, saberes essenciais para o enfrentamento das situações complexas do ensino e aprendizagem. A esse respeito, se pronuncia um dos professores: "[...] muitos não têm formação em licenciatura para dar apoio ao aluno. Porque o estudante na licenciatura, ao entrar no estágio, se não tiver nenhum apoio, pode se assustar. Vai chegar na escola e ter um impacto muito grande” (PC,2014). 
Não obstante, há que se ter em conta que os IFETs têm sua trajetória histórica de mais de 100 anos, consolidada pela formação vinculada à área técnica. Não bastará, portanto, uma simples mudança na lei para que os professores transformem suas práticas e concepções de educação, ensino e pesquisa. Os profissionais, que neles atuam em todos os níveis de ensino, são os mesmos, com as mesmas formações, atuando em um mesmo contexto sociocultural, ambiental e econômico, o que, por conseguinte, condicionam suas práticas. Ao falar sobre os desafios do trabalho com o ECS, o professor orientador justifica que se dá pelo "próprio perfil da instituição. Os IFETs não têm o perfil de formação de professores. É uma questão histórica, né? A condição de ser uma escola vinculada às questões técnicas. Eu acredito que não somente nós, mas outros institutos tenham estas dificuldades" (PC, 2014).

Os indicadores observados nesta pesquisa incitam a defesa na proposição da implantação de políticas públicas no IF que propiciem um processo de formação continuada dos formadores para que comecem a despertar sobre a imagem, a percepção de que são professores, não são somente agrônomos, biólogos, químicos, engenheiros, veterinários e estão professores. Afinal, há que se ter em conta que ensinar não é uma tarefa simples; ao contrário, o entendimento da complexidade da profissão docente obriga a avançar da ideia de qualquer um poder ser professor e que para dar aulas não se precisa preparar. Para Paniago e Sarmento (2016, p. 80), é importante que os saberes dos professores avancem de "[...] perspectivas disciplinares, conteúdos a ensinar, para saberes pedagógicos, do campo educacional, e porque não, um saber que vai muito além dos campos disciplinares, uma racionalidade capaz de dialogar com a arte, com o imaginário, com a afetividade, com a espiritualidade, com a história de vida dos alunos no contexto da diversidade".

Não obstante, entende-se que o ECS pressupõe ações pedagógicas supervisionadas de aprendizagem da docência, operacionalizadas em ambientes institucionais, futuro campo de trabalho dos formandos, com vistas a concretizarem a relação teoria-prática na construção dos saberes da docência. Estas ações devem ser supervisionadas por alguém que possui formação e prática do que está a supervisionar. Como um professor sem formação pedagógica ou experiência na educação básica vai operacionalizar o processo de orientação aos estagiários?

Neste sentido, advoga-se aqui a necessidade e importância da formação contínua, a fim de que todos os professores orientadores de estágio se preparem para o processo de orientação e percebam a importância do ECS no processo de formação do estagiário. Nesta linha de pensamento, um dos professores testemunha: "Um ponto que precisa ser melhorado, é conscientizar os próprios docentes de que essa prática é importante para a formação do licenciado” (PE, 2015).

\section{Potencialidades do atual modelo para a implantação do ECS pelo viés da pesquisa}

Aqui apresentar-se-ão as possibilidades do atual modelo de estágio do IF para a implantação do ECS, sob o viés da pesquisa pedagógica, que se traduzem pelo desenvolvimento de projetos, proposto no atual regulamento e o interesse dos formadores de o modificarem. 
O IF trabalha com os cursos de Licenciaturas nas áreas de Ciências Biológicas, Química, Matemática e Pedagogia em cinco de seus campi. No Campus lócus da pesquisa, são oferecidas as licenciaturas em Ciências Biológicas e Química nos turnos matutino, vespertino e noturno, cursos implantados a partir de 2008. O ECS, conforme os regimentos dos cursos de Química e de Biologia, é parte integrante e deve constituir-se em ações vinculadas ao ensino, pesquisa e extensão. De modo geral, a proposta expressa no regimento dos dois cursos totaliza uma carga horária efetiva de 400 (quatrocentas) horas de estágio, distribuídas em quatro semestres letivos. Dessas, 200 (duzentas) horas devem ser realizadas no ensino fundamental entre os $5^{\circ}$ (quinto) e $6^{\circ}$ (sexto) períodos; e 200 horas no Ensino Médio, entre os $7^{\circ}$ (sétimo) e $8^{\circ}$ (oitavo) períodos.

$\mathrm{Na}$ análise da documentação, percebeu-se que a discussão da perspectiva formativa da pesquisa é fomentada no ambiente institucional, fato consubstanciado nas ementas de algumas disciplinas de formação pedagógica, tais como Didática e Prática de Ensino e no regimento de estágio das Licenciaturas em Ciências Biológicas e de Química, neste caso, a evidência é por conta de neste documento se propor o trabalho com projetos de ensino durante o estágio.

Esse projeto de ensino é previsto para ser realizado sob a orientação do professor supervisor e orientador de estágio, com uma carga horária considerável (80 horas). O desenvolvimento de um projeto pelos estagiários revela-se como possibilidade do ensino via pesquisa, podendo ser o gerador de uma dinâmica de reflexão sobre a formação e atuação docente de modo mais direcionado pelo coletivo. Sobre isso, as estagiárias testemunham:

[...] participar dos projetos da escola foi importante, pois a gente pode entender como a direção gerencia e influencia as ações escolares. Isto me chamou a atenção, pois percebi que uma direção organizada e empenhada no bom trabalho facilita o dia a dia de todos os profissionais (Narrativa EA, 2013).

O estágio possibilitou um maior contato com o ambiente escolar e, principalmente, com os alunos e também foi importante para perceber as singularidades de cada indivíduo e cada turma. A fase de observação me permitiu ver quais as práticas os alunos gostam e ao trabalhar com projetos, procurei trabalhar o que eles gostavam. E gostei muito de trabalhar com projetos (Narrativa EJ, 2013).

As estagiárias expõem a importância do trabalho com projetos durante o estágio para o conhecimento da escola, da gestão e das singularidades de cada aluno. EJ clarifica que o estágio possibilita a inserção no cotidiano do trabalho docente e, por meio da observação, pode diagnosticar as necessidades dos alunos, seus desejos quanto às estratégias didáticas e através do trabalho com projetos, propor novas alternativas de trabalho em sala de aula.

Os alunos são orientados para a realização do projeto na disciplina de Prática de Ensino I e II, momento em que realizam um diagnóstico na escola. Esta fase constitui-se na observação, se configurando como o primeiro contato com a escola, período em que os estagiários observam a realidade educacional local nos seus aspectos socioculturais, analisam o 
Projeto Político Pedagógico da Escola, investigam as condições de ensino com foco na área de Ciências, Química e Biologia e elaboram o projeto de ensino de estágio. Nota-se que o diagnóstico da escola é base para o desenvolvimento das atividades do estágio.

Desta forma, o projeto de ensino, realizado na perspectiva diagnóstica durante o processo de ECS do IF, apresenta-se como um potencial significativo e pode se constituir em um espaço fértil para o desenvolvimento da investigação, se for complementado com reflexões coletivas, de modo a suscitar nos futuros professores a necessidade de refletir sobre temáticas emergentes no cotidiano da escola. Pimenta e Lima (2017, p. 229) corroboram, ao afirmarem que "A realização dos estágios sob a forma de projetos pode estimular nos estagiários o desenvolvimento de um olhar sensível e interpretativo às questões da realidade, uma postura investigativa [...]".

Em duas escolas conveniadas, foi possível observar que vários projetos foram desenvolvidos, focando o trabalho docente, especialmente, no ensino de Química e de Biologia; a Educação Ambiental; a implantação de hortas como instrumento pedagógico na escola, entre outros.

Outro elemento potencializador é o desejo dos professores de fazerem a diferença, por estarem iniciando a sua experiência com a formação de professores e a própria atuação em vários níveis de ensino. A atuação dos professores, em vários níveis e modalidades de ensino (Ensino Médio, Técnico, Proeja, Ensino Superior), mesmo sem formação específica e considerando as diversas complexidades traduzidas pelas inúmeras ementas, planejamentos, situações didáticas e forma de avaliar, pode contribuir para que vivenciem situações de ensino na educação básica com jovens dessa faixa etária, o que vai enriquecer os seus conhecimentos ao atuarem nas Licenciaturas. Ademais, por estarem começando, há uma inquietação por parte dos gestores e professores em busca de melhorias para o processo de formação de professores. Novóa $a^{3}$ contribui ao destacar seu olhar sobre as Licenciaturas nos IFETs:

[...] o movimento dos institutos federais, tal como eu pude perceber até agora no Brasil, é um movimento interessante, porque eu acho que são instituições que não têm ainda aquele peso tradicional de muitas universidades, em que os professores são muito céticos, já não acreditam em nada. [...] eu vi isso nos encontros que participei, que muitas pessoas que intervinham no final, a fazer perguntas, eram dos institutos federais. E a gente sente que muitas dessas pessoas que são dos institutos federais estão com uma dinâmica que às vezes, nas universidades já se perdeu.

É notável, na instituição, que a experiência recente com a formação de professores incita a gestão e os professores a buscarem novas alternativas de trabalho, que incluem, inclusive, o ECS, fato que motiva o grupo a propor uma perspectiva formativa do ECS pelo viés da pesquisa.

Ao falarem sobre a pesquisa na formação, os formadores afirmam que:

Não só é necessário quanto importante o contato do aluno a partir da metade do curso. No segundo período já se tem uma visão geral sobre essa questão, sobre os ser professor, sobre a pesquisa. Agora sem essa visão, essa base, a formação, o estágio assim fica prejudicado (PC, 2015). 
É fantástica a possibilidade da iniciação a pesquisa na graduação. Propor formas para os alunos durante o curso já desperta para a pesquisa em mais variadas áreas (PE, 2015).

De uma forma geral, há uma concordância entre os professores que a iniciação à pesquisa na formação é condição favorável e importante. Entretanto, eles não esclarecem qual o tipo de pesquisa a que se referem; seria pesquisa na sua área específica? Ou pesquisa na área da educação e/ou ensino? Então, procurouse identificar se os professores realizam práticas de pesquisa vinculada ao ensino. Apenas um professor afirmou que sim e ilustrou duas situações:

\footnotetext{
São trabalhos do tipo jogos relacionado ao ensino de Química. O primeiro trabalho foi desenvolvido com o grupo do PIBID de 2011, que é o projeto do Autrodómo Químico. E outro, foi um que relaciona com a parte interativa, a questão da informática, etc. Estamos analisando alguns sistemas que fazem experimentação virtual. Eles analisam os programas, percebem as falhas conceituais, o que tem de vantagem que facilita no entendimento do conceito (PC, 2014).
}

Como se observa, o professor cita as atividades de pesquisa que iniciou após o Programa Institucional de Bolsa de Iniciação a Docência (PIBID). Entretanto, não se pode dizer se estas atividades são apenas projetos de ensino ou se podem ser caracterizadas como iniciação à pesquisa. De uma forma ou de outra, constata-se que são ações que podem fomentar o trabalho com a pesquisa pedagógica, fato que demonstra que o PIBID está incitando novas práticas formativas na instituição. O PIBID, por meio da concessão de bolsas, tem como foco a formação do aluno da Licenciatura e a elevação da qualidade da formação de professores. O IF ingressou no programa em 2011, quando concorreu ao edital $n^{\circ}$ 001/2011/Capes/MEC e teve seu projeto aprovado, ou seja, dois anos após o início de oferecimento dos cursos de Licenciaturas. Sobre as aprendizagens oportunizadas no programa, relata outra professora orientadora "[...] o PIBID me despertou a vontade de fazer a pós graduação, pós doutorado na área de educação, o PIBID me abriu mais os meus olhos para esta área" (PL, 2015).

A partir de todos os pontos expostos, constatou-se além da existência de tensões e vulnerabilidades, várias possibilidades nas práticas de ECS no IF, potencializadoras da implantação de uma nova proposta pelo viés da pesquisa, que será apresentada a seguir.

\section{A nova proposta de ECS nas Licenciaturas do IF: um caminho de possibilidades}

A elaboração da nova proposta de ECS para os cursos de Licenciatura do IF contou com a participação de seis professores: dois do curso de Biologia, dois de Química e duas professoras da área de educação, incluindo as pesquisadoras. Por seis meses, o grupo se reuniu semanalmente para estudo dos princípios teóricos, epistemológicos do estágio, de experiências de outras instituições, reflexão sobre a problemática que envolvia o modelo existente, e, por fim, a (re)construção do regulamento de estágio das Licenciaturas. O ECS, com uma carga horária de 400 horas, passa a se constituir um elemento articulador da proposta curricular dos 
cursos de Licenciatura. Esta carga horária foi distribuída em 4 semestres letivos no Ensino Fundamental e Médio, a saber:

ETAPA 1: Estágio Curricular Supervisionado do Ensino Fundamental - $5^{\circ}$ (Quinto) semestre do curso - 100 horas a serem cumpridas nos anos finais do Ensino Fundamental $\left(6^{\circ}\right.$ a o $9^{\circ}$ ano $)$.

ETAPA 2: Estágio Curricular Supervisionado do Ensino Fundamental - $6^{\circ}$ (Sexto) semestre do curso - 100 horas a serem cumpridas nos anos finais do Ensino Fundamental $\left(6^{\circ}\right.$ a o $9^{\circ}$ ano $)$.

ETAPA 3: Estágio Curricular Supervisionado do Ensino Médio - $7^{\circ}$ (Sétimo) semestre do curso - 100 horas a serem cumpridas nos anos do Ensino Médio.

ETAPA 4: Estágio Curricular Supervisionado do Ensino Médio - $8^{\circ}$ (Oitavo) semestre do curso - 100 horas a serem cumpridas nos anos do Ensino Médio (Regulamento estágio IF, 2014, p. 2).

As 100 horas de cada etapa são configuradas em fases. As etapas 1 e 3 são semelhantes e são operacionalizadas de acordo com o quadro abaixo:

\begin{tabular}{|c|c|c|c|l|}
\hline Semestre & $\begin{array}{c}\text { Quantidade } \\
\text { de horas }\end{array}$ & $\begin{array}{c}\text { Distribuição } \\
\text { de horas }\end{array}$ & Fases & Atividades \\
\hline \multirow{2}{*}{$5^{\circ}$ e 70} & 100 & 30 & B & $\begin{array}{l}\text { Orientação, acompanhamento e } \\
\text { elaboração de pré-projeto de estágio } \\
\text { e relatório }\end{array}$ \\
\cline { 3 - 6 } & 100 & 10 & C & Observação do professor e diagnóstico da escola \\
\cline { 3 - 5 } & & 30 & & \\
\hline
\end{tabular}

Fonte: (Regulamento estágio IF, 2014, p.16).

As 60 horas são destinadas à orientação de ECS pelos professores orientadores de estágio. Esta orientação tem como finalidade a preparação dos estagiários para a aproximação do cotidiano da escola de educação básica, de forma questionadora, reflexiva e investigativa. A intenção é que, antes de adentrarem na escola, sejam orientados a respeito de uma proposta com vistas para o trabalho com projetos de intervenção e/ou de pesquisa. Serão orientados a levantar dados, observação, análise, interpretação e sistematização. Ademais, nas etapas 1 e 3, vão elaborar um projeto a ser implementado nas etapas 2 e 4. Além do processo de supervisão do professor orientador, os estagiários "terão o suporte da disciplina de Pesquisa e Práticas de Intervenção em Educação I e II, que ocorrerá concomitante às etapas 1 e 3 do estágio e terá, dentre uma das suas 
finalidades, a orientação das práticas de ensino a serem desenvolvidas no ECS" (Regulamento estágio IF, 2014, p. 20). Então, com vistas à concretização do ECS via pesquisa, foi criada esta disciplina para que os estagiários recebam orientação para a realização do diagnóstico, sobre as técnicas e instrumentos para a recolha dos dados, planejamento e elaboração do pré-projeto de ensino.

A esse respeito, Almeida e Pimenta (2014) corroboram, ao pressuporem que a incursão no universo da escola implica uma proposição orientadora para a pesquisa. "Ter uma questão-problema é fundamental para a orientação do olhar do licenciando quando chegam à escola e, particularmente, à sala de aula, uma vez que esses universos são complexos [...]” (ALMEIDA; PIMENTA, 2014, p. 30).

Já as etapas 2 e 4 serão realizadas de acordo com o seguinte quadro:

\begin{tabular}{|c|c|c|c|c|}
\hline Semestre & $\begin{array}{l}\text { Quantidade } \\
\text { de horas }\end{array}$ & $\begin{array}{l}\text { Distribuição } \\
\text { de horas }\end{array}$ & Fases & Atividades \\
\hline \multirow{4}{*}{$6^{\circ}$ e $8^{\circ}$} & \multirow{4}{*}{100} & 60 & A & $\begin{array}{l}\text { Orientação, acompanhamento } \\
\text { e elaboração do relatório. }\end{array}$ \\
\hline & & 10 & $\mathrm{~B}$ & Regência Ensino Fundamental \\
\hline & & 20 & $\mathrm{C}$ & Desenvolvimento do projeto de estágio \\
\hline & & 10 & $\mathrm{D}$ & Elaboração do relatório. \\
\hline
\end{tabular}

Fonte: (Regulamento estágio IF, 2014, p. 18).

Encerradas as etapas 1 e 3, os estagiários realizam o diagnóstico na escola, observam as práticas de sala de aula dos professores titulares e elaboram o projeto de ensino. $\mathrm{Na}$ etapa 2 e 4, eles irão operacionalizar as práticas efetivas em sala de aula nos anos finais do Ensino Fundamental e Ensino Médio, respectivamente, bem como o desenvolvimento do projeto de ensino.

Importante salientar que, ao final de cada etapa de estágio, serão realizados seminários, com vistas à socialização da experiência e aprendizagens construídas sobre o ser professor. Ademais, o IF vem trabalhando, institucionalmente, um evento sobre a pesquisa e práticas em educação, como forma de suscitar a produção acadêmica na área de educação.

Por certo, a compreensão que ancora esta proposta é a de que o ECS se configura como práxis, um momento-chave na formação que se operacionaliza por meio de estudos, reflexões e investigações. A asserção de Almeida e Pimenta (2014) é pertinente ao dizerem que entendem o ECS como:

[...] um campo de conhecimento que envolve estudos, análise, problematização, reflexão e proposição de soluções para o ensinar e o aprender, e que compreende a reflexão sobre as 
práticas pedagógicas, o trabalho docente e as práticas institucionais, situados em contextos sociais, históricos e culturais (ALMEIDA; PIMENTA, 2014. p. 20).

Em cômputo geral, avançou-se, em demasiado, nas discussões e operacionalização do ECS no seio do IF. Entretanto, enfatiza-se a necessidade e importância da formação contínua dos formadores e a implementação colaborativa na IES, rede estadual e municipal de ensino, de um processo de formação continuada, ancorado nos princípios de uma formação reflexiva e crítica de professores, em que a formação é espaço de reflexão, pesquisa, intervenção e transformação. Nesta perspectiva, a prática portuguesa com o ECS, aliada à investigação, pode apoiar esta discussão; conforme afirma Alarcão (2011), ao propor que este processo pode ocorrer por meio da escola reflexiva colaborativa que faça emergir o professor investigador. Para tanto, a autora propõe a pesquisa-ação e outras estratégias, tais como: a análise de casos, as narrativas, a construção de portfólios, os grupos de discussão, a auto-observação, a supervisão colaborativa e as perguntas pedagógicas.

A partir dos resultados aqui apresentados, acerca das fragilidades, potencialidades e nova proposta de ECS, no futuro, serão apresentados os resultados da fase que se encontra em execução, nomeadamente, o acompanhamento perspectivado na pesquisa-ação das práticas dos estagiários sob o viés da pesquisa.

\section{CONSIDERACְÕES FINAIS}

A pesquisa inicial aponta investigações em vários sentidos, envolvendo o conhecimento da realidade pelo grupo propositor da nova proposta de ECS no IF visando: i) o estudo sobre como se desenvolve o estágio, atualmente, nas licenciaturas; ii) a análise dos resultados de tais propostas no desenvolvimento e formação dos novos professores, a qual não pode ser distanciada da realidade; iii) o investimento na formação continuada dos professores incluído a formação para a pesquisa; iv) diálogos com os professores sobre as decisões coletivas e sua implementação; e v) o acompanhamento do desenvolvimento da proposta em ampla assessoria aos professores sob a forma de pesquisa ação.

Os resultados, apresentados no presente estudo, apontaram que o estágio vem sendo realizado dentro de uma concepção da racionalidade técnica, tendo em vista que a falta de conexão das atividades de pesquisa dos docentes com as atividades de ensino e a inexistência da coletividade para discutir, refletir sobre as ações de estágio, não contribui para o desenvolvimento do estágio via pesquisa. Ademais, a pesquisa apontou que uma das fragilidades fulcrais se refere à ausência de trabalho colaborativo e formação pedagógica dos formadores.

Para a sua superação, a fim de que possa desenvolver-se, associado à pesquisa durante a Licenciatura, propõe-se: contemplar esta proposta no Projeto Político Pedagógico da Instituição; tratar o ECS como elemento articular que se materializa associado ao trabalho com a Prática como Componente Curricular (PCC); fazer com que o ECS permeie todas as disciplinas, tendo como princípio a formação na e para a pesquisa; realizar formação continuada com os orientadores de estágio; promover reflexões coletivas para planejamento, execução e avaliação das ações, evidenciando, assim, o estágio com pesquisa como uma proposta que 
destaca o compromisso do IF com a formação do licenciando e a aproximação com o modelo da racionalidade prática e crítica. A partir da realidade estudada, o grupo pretende, com a proposta de estágio-pesquisa, superar a racionalidade técnica e, gradativamente, promover a inserção do ECS na perspectiva da racionalidade prática e crítica.

Entende-se que a vinculação do estágio com a pesquisa possibilita, aos futuros professores, aproximarem-se da realidade na qual atuarão, numa perspectiva de práxis, em que ocorre a superação da dicotomia entre teoria e prática para um processo em que a teoria é suporte à problematização das situações vivenciadas nas organizações educativas e nas práticas de sala de aula, clarificando as perspectivas de análise. O ECS, pelo viés da pesquisa, possibilita, aos licenciandos, a realização de projetos de ensino, projetos de intervenção após a fase de diagnóstico, observação e, por conseguinte, desses projetos poderão ser gestados projetos de pesquisa.

No diálogo com teóricos, como já dissemos, identificam-se vários autores que defendem a necessidade e importância do estágio pelo viés da pesquisa e experiências já consolidadas, tais como Pimenta e Lima (2017), Lima e Costa (2014), Vieira (2015), Ghedin e Almeida (2011) Almeida e Pimenta (2014), dentre outros. Entretanto, de modo geral, estas discussões são tecidas no contexto de cursos de Pedagogia de instituições de ensino superior com experiência alongada com a formação inicial de professores, salvo Fernandes e Quadro (2016), Paes (2017) que discutem o ECS nos IFETs. No tocante ao trabalho com estágio perspectivado na presente investigação e na reflexão, acredita-se que esta pesquisa avança por trazer esta discussão com cursos de áreas específicas e no seio de uma instituição com recente experiência com a formação inicial de professores e com fortes raízes históricas da formação técnica e profissionalizante, em que há prevalência das Ciências Agrárias, da formação técnica numa concepção de pesquisa vinculada a uma "epistemologia e a metodologias positivistas das ciências naturais” (SANTOS, 2005, p. 68).

\section{REFERÊNCIAS}

ALARCÃO, I. Professores reflexivos em uma escola reflexiva. 8a ed. São Paulo: Cortez, 2011.

ALMEIDA, Mª I.; PIMENTA, S.G. Estágios supervisionados na formação docente. São Paulo: Cortez, 2014.

BRASIL. Resolução CNE/CP Nº̂n de 18 de fevereiro de 2002 - Institui as Diretrizes Curriculares Nacionais para a Formação de Professores da Educação Básica, em nível superior, curso de licenciatura, de graduação plena.

BRASIL. Lei 11.892 de 29 de dezembro de 2008 - Institui a Rede Federal de Educação Profissional, Científica e Tecnológica, cria os Institutos Federais de Educação, Ciência e Tecnologia, e dá outras providências. Brasília, 2008.

BRASIL. Resolução CNE/CP no 02 de 1 de julho de 2015. Define as Diretrizes Curriculares Nacionais para a formação inicial em nível superior e para a formação continuada. Diário Oficial [da] União, Brasília2015. 
DINIZ-PEREIRA, J., E.; LACERDA M. P. Possíveis significados da pesquisa na prática docente: ideias para fomentar o debate. Revista Educ. Soc., Campinas, v. 30, n.109, p. 1229-1242, set/ dezembro, 2009. Acesso em: 10 ago. 2014.

GHEDIN, E.; FRANCO, M. A. S. Questões de método na construção da pesquisa em educação. São Paulo: Cortez, 2008.

GHEDIN, E.; ALMEIDA, W. A. de. O estágio com pesquisa na formação do professor-pesquisador para o ensino de ciências numa experiência campesina. In: GOMES, M. de O. (org.). Estágios na formação de professores: possibilidades formativas entre ensino, pesquisa e extensão. São Paulo: Loyola, 2011, p.46-78.

IF. Projeto Político Pedagógico. 2009. Disponível em: <www.rioverde.ifgoiano.edu.br> Acesso em: 17 fev. 2012.

IF. Matrizes curriculares dos cursos de licenciatura em Biologia e Química. 2010.

IF. Regulamento dos cursos de licenciatura em Química e Ciências Biológicas. 2010.

IF. Regulamento dos cursos de licenciatura em Química e Ciências Biológicas. 2014.

KINCHELOE, J. L. A formação do professor como compromisso político: mapeando o PósModerno. Porto Alegre: Artes Médicas, 1993.

LUDKE, M. Universidade, escola de educação básica e o problema do estágio na formação de professores. Formação Docente. Belo Horizonte, v. 01, n. 01, p. 95-108, ago./dez. 2009.

LIMA, M.S.; AROEIRA, K. P. O estágio curricular em colaboração, a reflexão e o registro dos estagiários: um diálogo entre a universidade e a escola. In: GOMES, M. de O. (org.). Estágios na formação: possiblidades formativas entre ensino, pesquisa e extensão. São Paulo, Edições Loyola, 2011.

NÓVOA, A. Nada substitui um bom professor: propostas para uma revolução no campo da formação de professores. In: Gatti, B. A. et al. Por uma política nacional de formação de professores, 2013, p. 199-210. São Paulo: Unesp.

NÓVOA, A. Entrevista concedida à $1^{\text {a }}$ pesquisadora em Lisboa, Portugal, Janeiro de 2014.

PAES, I. F. Mobilizações no processo de estágio supervisionado na formação inicial de professores: reflexos de experiências no Instituto Federal Fluminense. Tese de doutorado. Universidade Estadual de Campinas. Faculdade de Educação. 2017.

PANIAGO, R.; SARMENTO, T. O processo de estágio supervisionado na formação de professores portugueses e brasileiros. Revista Educação em Questão, Natal, v. 53, n. 39, p. 76-103, maio/ago. 2015. Acesso em: 20 set 2015.

PIMENTA, S. G.; LIMA, M. S. L. Estágio e Docência. 8ª ed. São Paulo: Cortez, 2017.

PORTUGAL. Decreto-Lei $\mathbf{n}^{\circ}$ 43, de 22 de fevereiro. Regime Jurídico da habilitação profissional para a docência na educação pré-escolar e nos ensinos básico e secundário, 2007.

SANTOS, B. S. Um discurso sobre as ciências. $3^{a}$ ed. São Paulo: Cortez, 2005.

SARMENTO, T; PANIAGO, R.. A investigação ao serviço das práticas como componente central no processo de aprendizagem profissional. Reflexão e Ação, Santa Cruz do Sul, v. 24, n. 3, p. 47-69, set./dez. 2016. 
SILVA, F. L. G. R. ; FERNANDES, S.R.; QUADROS, S. F. A formação de pedagogos no IFC: o estágio supervisionado em gestão como articulador da práxis. Anais XVIII ENDIPE Didática e Prática de Ensino no contexto político contemporâneo: cenas da Educação Brasileira, 2016, p.1778. In: http://www.ufmt.br/endipe2016/downloads/233_10737_36506.pdf. Acesso em: 07 jul. 2018.

TARDIF, M. Saberes docentes e formação profissional. 15ª ed. Petrópolis, RJ: Vozes, 2013.

VIEIRA, F. Entrevista concedida a 1 ${ }^{a}$ pesquisadora em 12 de dezembro de 2015 na Universidade do Minho, Braga, Portugal.

ZEICHNER, K. M. Repensando as conexões entre a formação na universidade e as experiências de campo na formação de professores em faculdades e universidades. Educação, Santa Maria, v. 35, n, 3, 2010, p. 479-504.

\section{NOTAS}

${ }^{1}$ Para Alarcão (2011, p. 52) a "pesquisa-ação é uma metodologia de intervenção social cientificamente apoiada e desenrola-se segundo ciclos de planificação, ação, observação [...]”. Segundo a autora, após a compreensão da problemática, recorre-se ao planejamento da intervenção, em seguida, à observação, o que vai gerar novos conceitos, problemas, novo planejamento e replanejamento, em uma perspectiva espiral de pesquisa-ação.

${ }^{2}$ Para Ponte (2006, p. 19-20): O chamado Processo de Bolonha, subscrito presentemente por cerca de quarenta países, afirma o seu empenhamento na construção de um espaço europeu de ensino superior tendo em vista a qualidade, a mobilidade e a comparabilidade dos graus académicos e formações. Para isso, os países signatários propõem-se adoptar um sistema de diplomas claros e compatíveis, organizar os estudos em três ciclos de formação (correspondentes aos graus de bachelor, mastere doctor), desenvolver um controlo comparável da qualidade da formação e reforçar a dimensão européia.

${ }^{3}$ Entrevista realizada pela primeira pesquisadora, em Lisboa, janeiro de 2014.

\section{Submetido em 16/04/2018}

Aprovado em 24/07/2018

\section{Contato:}

Rosenilde Nogueira Paniago

Rua: RC 11, lote 24, quadra 20, $n^{0} 333$ - Residencial Canaã

Caixa Postal: $n .275$

CEP: 75.901-970 - Rio Verde, GO - Brasil 